\title{
Determining of Turfgrass Performance of Certain Tall Fescue Cultivars in Cool Season Ecological Conditions
}

\author{
${ }^{* 1}$ Mustafa YILMAZ \\ ${ }^{1}$ Sakarya University, Pamukova Vocational School, Sakarya, Turkey, \\ mustafayilmaz@sakarya.edu.tr,
}

Research Paper

Received Date: 21.02.2018

Accepted Date: 27.07.2018

\begin{abstract}
This study was conducted to determine the turfgrass performance of newly introduced tall fescue (Festuca arundinacea Schreb.) cultivars in the ecological conditions of the cool climate. The experiment was carried out in the Plant Cultivation garden of the Parks and Gardens Directorate of Tokat Municipality for 3 years between May 2009 - January 2012. Six different tall fescue cultivars (Apache, Eldorado, Firaces, Merida, SR8600 and Turbo) were used. In the study; turf cover ratio, weed invasion density, turf color, winter endurance and turf quality characteristics were measured with scores between 1-9 point, and turf texture was measured in $\mathrm{mm}$. Study results showed that the highest values were obtained from the Merida and Turbo cultivars and that, generally speaking, the other cultivars could easily be used in turf establishment in the region and in similar ecological conditions.
\end{abstract}

Keywords: Cool season turfgrasses, tall fescue, turf cover, weed invasion, turf color, turf texture, turf quality.

\section{INTRODUCTION}

Most modern societies prefer living in natural environments and benefiting from their physical and psychological health advantages. People desire to live in cities for various reasons, which in turn results in extensive construction of buildings. Density of concrete structures such as buildings, roads, pavements or similar structures, and the resulting yearning for decreasing green areas grows by the day. The importance of green areas, which enhance visual pleasure, contentment and physical well-being has gradually increased particularly in recent years and establishment areas have expanded [1,2].

Turf plants, the biggest botanical presence surrounding our living environments, are used in vast areas not just in our country but also in developed countries and in addition to their physical and spiritual relaxation qualities, they create much needed areas of rest. The usage areas of turf areas, which are a part of our lives with their esthetic, functional and recreational effects, are constantly increasing [2]. Turf areas are established for various different purposes such as parks-gardens, airports, roadsides, resorts' gardens, hotels and especially for playfields of sports like soccer, tennis, golf, hockey, ski and so forth.
We can see diverse plant species and varieties creating green area texture around us. Trees, shrubs, bushes and groundcover plants are without a doubt the most valuable elements which embellish the living spaces of the areas they inhabit. The highest share is constituted by turfgrass plants, which are among groundcover and erosionpreventive plants used in landscaping Additionally, turfgrass plants live in harmony with their surroundings and once they have adapted to the conditions, can form a healthy and high-grade vegetation. That the same turf species and varieties can be planted in almost any district of regions with differing ecological conditions is an erroneous notion which exists in our country $[1,2,3,4]$.

Tall fescue has particular importance among plants that can be used in the establishment of turf areas and is known for its coarse structure, fescue life form and adaptability to different climate and soil conditions. It is a genus which has wide leaf blades, non-frequent tillering, a dark green color, very dense, strong and deep roots and is generally unsuitable for mixing. As it shows high endurance against shade and adaptability to arid and saline soils, it is the optimal plant for use in equestrian sports' fields, road slopes, airports and particularly in problematic areas or in circumstances where a turf area is to be created with little maintenance and a low budget $[1,2,3,4]$. Several researchers 
studying on the tall fescue [3-26] evaluated the plant's general green area appearance with a score between 3-9, and offered explanatory information about its turf area performance.

This study was carried out with the aim of assessing the performance of certain tall fescue (Festuca arundinacea Schreb.) cultivars, introduced in recent years, in the ecological conditions of the cool climate province of Tokat in Turkey.

\section{MATERIAL AND METHODS}

The study was conducted in the province of Tokat $\left(40^{\circ} 19^{\prime}\right.$ $34.80^{\prime \prime} \mathrm{N}, 36^{\circ} 33^{\prime} 18.26^{\prime \prime} \mathrm{E}$ and $623 \mathrm{~m}$ above sea level), located in a transition zone between the Central Black Sea and Central Anatolia Regions.

The experiment was established in the Plant Cultivation garden of the Parks and Gardens Directorate of Tokat Municipality. Mean climate data values have been listed in Table 1.

Table 1. The climate dates of Tokat Province for 20092012 years and Long Term Average (LTA)*

\begin{tabular}{cccc}
\hline Years & $\begin{array}{c}\text { Total } \\
\text { precipitaion } \\
(\mathbf{m m})\end{array}$ & $\begin{array}{c}\text { Climatic factors } \\
\text { Average } \\
\text { temperature } \\
\left({ }^{\circ} \mathbf{C}\right)\end{array}$ & $\begin{array}{c}\text { Moisture } \\
(\%)\end{array}$ \\
\hline $\mathbf{2 0 0 9}$ & 481.4 & 13.1 & 62.8 \\
$\mathbf{2 0 1 0}$ & 476.8 & 12.8 & 63.1 \\
$\mathbf{2 0 1 1}$ & 480.5 & 13.0 & 61.9 \\
$\mathbf{2 0 1 2}$ & 475.6 & 12.5 & 61.0 \\
\hline LTA $^{*}$ & $\mathbf{4 4 5 . 5}$ & $\mathbf{1 2 . 4}$ & $\mathbf{6 2 . 2}$ \\
\hline
\end{tabular}

Analyses of soil samples taken from 0-20 cm depths of the research area were conducted in the Middle Black Sea Transitional Zone Agricultural Research Institute's Laboratory, and were classified according to Brohi ve Aydeniz [27] The soils indicated national-loamy structure, were very slightly alkaline ( $\mathrm{pH}: 7.3)$, non-saline (0.022\%), medium alkaline $(9.1 \%)$, insufficient in terms of available phosphorus (11.24 $\left.\mathrm{kg} \mathrm{ha}^{-1}\right)$, sufficient in terms of potassium $\left(279 \mathrm{~kg} \mathrm{ha}^{-1}\right)$ and at a medium level in terms of organic substances $(1.55 \%)$.

Six different newly introduced tall fescue cultivars (From Semillas Fito Co.; Firaces, Merida, Turbo, From DLF Trifolium Co.; Apache, Eldorado, From SRO Co.; SR8600) were used as vegetational materials in the study, and sowing was carried out by use of $20 \mathrm{~g} \mathrm{~m}^{-2}$ sowing norm, with consideration to germination percentages [1,2]. The study was carried out for 3 years from 30 March, 2009 to 15 January, 2012. Plot sizes were $2 \times 1 \mathrm{~m}\left(2 \mathrm{~m}^{2}\right)$ and $50 \mathrm{~cm}$ spaces were left in between plots. For an annual NPK fertilization dosage of 25-15-15 $\mathrm{g} \mathrm{m}^{-2}$, recommended by Acikgoz [1] and [2] and supported by certain research $[13,25]$ results as the appropriate amount in the ecological conditions of Tokat, 15-15-15 compound and a 26\% ammonium nitrate was used, the fertilizer was divided into 14 equal shares and was applied every 15 days from April to September.

Irrigation was applied using automatic rotary sprinklers. Upon reaching heights of 6-10 cm, plants were mown at a height of $4 \mathrm{~cm}$ with a gas lawn mower, 20 times per year (spring 7, summer 6, autumn 7 and winter 0 ).

Turf cover ratio (1: very sparse, 9: very dense), weed invasion density (1: very high, 9: very low), turf color (1: yellow, 9: dark green), winter endurance and general turf quality (1: very bad, 9: very good) traits were assessed with scores based on a 1-9 scale and classification was as follows: 8-9 very good, 7.9-7 good, 6.9-6 medium, 5.9-5 acceptable, and 5 or below unacceptable $[1,2,3,4]$. Texture, which is the measurement of the widest section of leaf blade, (in 10 randomly selected plants from each plot for each measurement) was measured in $\mathrm{mm}$ [3,28]. (Beard, 1973; Morris and Sherman, 2000). Observations were conducted in all four seasons, on the following dates; Spring (Sp) - 15 April, Summer (Su)- 15 July, Autumn (Au)- 15 September and Winter (Wi)- 15 January.

A Two-Way Randomized Block Experimental Design with four replications was established, statistical analyses of the results obtained at the end of the study were performed using the TOTEMSTAT Statistical Program [29]. (Acikgoz et al., 2004) and LSD values (5\%) were stated underneath the Tables.

\section{RESULTS}

\subsection{Turf Cover}

Mean cover values of the $1^{\text {st }}, 2^{\text {nd }}$ and $3^{\text {rd }}$ years, as well as the three years mean values were given in Table 2 .

When the figures were assessed in terms of cultivars, the Merida and Turbo cultivars displayed highest cover scores with 8.2 the first year, 8.9 the second year, a perfect score of 9.0 the third year and a mean score of 8.7, while Apache and Firaces had lowest values with 7.6 the first year, 8.5 the second year, 8.7 the third year and a mean score of 8.3.

Results showed that, on the basis of seasons, highest values were obtained in autumn and spring. Low scores in the spring of the first year were specifically because the green area had newly been established and plants had just begun tillering, and thus hadn't covered the area to their full capacity. 
Table 2. Turf Cover and Weed Invasion Scores by Seasons in Different Years (1-9 scale)

\begin{tabular}{|c|c|c|c|c|c|c|c|c|c|c|c|c|c|c|c|}
\hline \multirow[b]{3}{*}{ Years } & \multirow[b]{3}{*}{$\mathbf{S}$} & \multicolumn{7}{|c|}{ Turf Cover* } & \multicolumn{7}{|c|}{ Weed Invasion ${ }^{* *}$} \\
\hline & & & & & ultiv: & & & & & & & Cultiva & & & \\
\hline & & Ap. & El. & Fi. & Me. & SR. & Tu. & Mean & Ap. & El. & Fi. & Me. & SR. & Tu. & Mean \\
\hline \multirow{5}{*}{$\begin{array}{c}1 . \\
\text { year }\end{array}$} & $\mathrm{Sp}$ & 5.5 & 5.8 & 5.5 & 6.5 & 6.1 & 6.6 & 6.0 & 6.1 & 6.3 & 6.4 & 6.5 & 6.4 & 6.6 & 6.4 \\
\hline & $\mathrm{Su}$ & 8.2 & 8.4 & 8.3 & 8.8 & 8.5 & 8.8 & 8.5 & 7.2 & 7.4 & 7.5 & 7.8 & 7.5 & 7.8 & 7.5 \\
\hline & $\mathrm{Au}$ & 8.4 & 8.5 & 8.4 & 9.0 & 8.8 & 9.0 & 8.7 & 8.5 & 8.6 & 8.5 & 9.0 & 8.8 & 9.0 & 8.7 \\
\hline & Wi & 8.1 & 8.3 & 8.2 & 8.6 & 8.4 & 8.5 & 8.4 & 8.6 & 8.8 & 8.7 & 9.0 & 9.0 & 9.0 & 8.9 \\
\hline & Me. & 7.6 & 7.8 & 7.6 & 8.2 & 8.0 & 8.2 & 7.9 & 7.6 & 7.8 & 7.8 & 8.1 & 7.9 & 8.1 & 7.9 \\
\hline \multirow{5}{*}{$\begin{array}{c}2 . \\
\text { year }\end{array}$} & $\mathrm{Sp}$ & 8.6 & 8.5 & 8.7 & 8.9 & 8.8 & 8.9 & 8.7 & 8.5 & 8.4 & 8.6 & 9.0 & 8.8 & 9.0 & 8.7 \\
\hline & $\mathrm{Su}$ & 8.4 & 8.4 & 8.5 & 8.8 & 8.7 & 8.8 & 8.6 & 8.8 & 8.7 & 8.9 & 9.0 & 8.9 & 9.0 & 8.7 \\
\hline & $\mathrm{Au}$ & 8.8 & 8.8 & 8.6 & 9.0 & 8.9 & 9.0 & 8.9 & 8.9 & 8.8 & 8.9 & 9.0 & 8.9 & 9.0 & 8.7 \\
\hline & Wi & 8.3 & 8.5 & 8.3 & 8.7 & 8.5 & 8.8 & 8.5 & 8.7 & 8.8 & 8.8 & 9.0 & 8.8 & 9.0 & 8.7 \\
\hline & Me. & 8.5 & 8.6 & 8.5 & 8.9 & 8.7 & 8.9 & 8.7 & 8.7 & 8.7 & 8.8 & 9.0 & 8.9 & 9.0 & 8.7 \\
\hline \multirow{5}{*}{$\begin{array}{c}3 . \\
\text { year }\end{array}$} & $\mathrm{Sp}$ & 8.7 & 8.8 & 8.7 & 9.0 & 8.9 & 9.0 & 8.9 & 8.6 & 8.5 & 8.7 & 9.0 & 8.9 & 9.0 & 8.8 \\
\hline & $\mathrm{Su}$ & 8.7 & 8.7 & 8.7 & 9.0 & 8.8 & 9.0 & 8.8 & 8.8 & 8.8 & 8.9 & 9.0 & 8.9 & 9.0 & 8.9 \\
\hline & $\mathrm{Au}$ & 8.8 & 8.9 & 8.8 & 9.0 & 8.9 & 9.0 & 8.9 & 8.9 & 8.9 & 8.9 & 9.0 & 8.9 & 9.0 & 8.9 \\
\hline & Wi & 8.7 & 8.7 & 8.7 & 9.0 & 8.9 & 9.0 & 8.8 & 8.8 & 8.8 & 8.8 & 9.0 & 8.8 & 9.0 & 8.9 \\
\hline & Me. & 8.7 & 8.8 & 8.7 & 9.0 & 8.9 & 9.0 & 8.9 & 8.8 & 8.8 & 8.8 & 9.0 & 8.9 & 9.0 & 8.9 \\
\hline \multirow{5}{*}{ Mean } & $\mathrm{Sp}$ & 7.6 & 7.7 & 7.6 & 8.1 & 7.9 & 8.2 & 7.9 & 7.7 & 7.7 & 7.9 & 8.2 & 8.0 & 8.2 & 8.0 \\
\hline & $\mathrm{Su}$ & 8.4 & 8.5 & 8.5 & 8.9 & 8.7 & 8.9 & 8.6 & 8.3 & 8.3 & 8.4 & 8.6 & 8.4 & 8.6 & 8.4 \\
\hline & $\mathrm{Au}$ & 8.7 & 8.7 & 8.6 & 9.0 & 8.9 & 9.0 & 8.8 & 8.8 & 8.8 & 8.8 & 9.0 & 8.9 & 9.0 & 8.8 \\
\hline & Wi & 8.4 & 8.5 & 8.4 & 8.8 & 8.6 & 8.8 & 8.6 & 8.7 & 8.8 & 8.8 & 9.0 & 8.9 & 9.0 & 8.8 \\
\hline & Me. & 8.3 & 8.4 & 8.3 & 8.7 & 8.5 & 8.7 & 8.5 & 8.4 & 8.4 & 8.5 & 8.7 & 8.6 & 8.7 & 8.7 \\
\hline \multicolumn{2}{|c|}{ "LSD 5\% } & $C: 0.01$ & & $S: 0.03$ & & $Y: 0.02$ & & $C \times S$ & & $C \times Y$ & & $S \times Y$ & & $C \times S \times$ & 0.05 \\
\hline \multicolumn{2}{|c|}{ *LSD 5\% } & $C: 0.02$ & & $S: 0.02$ & & $Y: 0.02$ & & $C \times S: C$ & & $C \times Y$ & 03 & $S \times Y:$ & 02 & $C \times S \times$ & 0.06 \\
\hline
\end{tabular}

Ap.: Apache, El.: Eldorado, Fi.: Firaces, Me.: Merida, SR.: SR8600, Tu.: Turbo, M.: Means,

Sp.: Spring, Su.: Summer, Wi.: Winter, Au.: Autumn, C.: Cultivar, S.: Season, Y.: Year.

If spring of the first year (6.0) is to be excluded for the reason mentioned above, the lowest values were observed in winter. However, the low score of spring of the first year led to a mean score of 7.9. Plants showed their true performance in autumn and spring, hence cover area rates increased.

When data was analyzed in terms of cultivar $\times$ season interactions, the Merida and Turbo cultivars achieved highest values with a perfect score (9.0) in the autumn of all three years and a mean value of 8.7 , whereas the lowest value was attained from the Apache and Firaces cultivars in spring (5.5) of the first year, and in winter of the second and third years (8.3 and 8.7).

When assessed with regard to years, data showed that mean values increased from the first year on $(7.9,8.7,8.9)$ and the general average was 8.5 (Table 2). As was mentioned when discussing seasons, this was due to the period of time lost for turf plants to cover the area particularly in spring of the establishment year.

\subsection{Weed Invasion}

Weed invasion density data for all three years of the study and the mean values have been presented in Table 2. In terms of cultivars, the Merida and Turbo cultivars emerged as those which do not allow weeds to invade their plots with a score of 8.1 in the first year, and a perfect score of 9.0 in the second and third years, while Apache, which scored 7.6 the first year, along with Eldorado in the second and third years, were the cultivars with the lowest values.

Results show that, on the basis of seasons, for all the years spring was the season in which weed invasion density was highest. Weeds were denser in spring and partially in the cool period of autumn particularly in the first year because an increase in rainfall and temperatures during the early growth period of turf allowed annual weed seeds present in the experiment field soil to germinate and grow. With the germination of turf, weed density continually decreased and in the second year decreased to almost non-existing levels. It can be said that after the first year of establishment, all varieties competed strongly with weeds and covered the area in such a way as to inhibit weed germination.

When data was assessed with regard to years, the 3rd year (8.9) reached higher scores than the 2nd (8.7) and 1st (7.9) years. As was mentioned when discussing the seasons, this is because turf plants had to compete with weeds in the establishment year before accomplishing to cover the entire area and could not fully show their true performance.

When data was assessed in terms of cultivar $\times$ season interactions, the Merida and Turbo cultivars in autumn of 
the first year, accompanied by the SR8600 cultivar in winter, achieved the highest score (9.0).

In all seasons of the second and third year, the perfect scores were obtained Merida and Turbo cultivars.

\subsection{Turf Color}

Color values for all three years of the study and the means values have been listed in Table 3 .

Table 3. Turf Color (1-9 scale) and Turf Texture (mm) Scores by Seasons in Different Years

\begin{tabular}{|c|c|c|c|c|c|c|c|c|c|c|c|c|c|c|c|}
\hline \multirow[b]{3}{*}{ Years } & \multirow[b]{3}{*}{$\mathbf{S}$} & \multicolumn{7}{|c|}{ Turf Color* } & \multicolumn{7}{|c|}{ Turf Texture $^{* * *}$} \\
\hline & & & & & ultiva & & & & & & & Cultiv & & & \\
\hline & & Ap. & El. & Fi. & Me. & SR. & Tu. & Mean & Ap. & El. & Fi. & Me. & SR. & Tu. & Mean \\
\hline \multirow{5}{*}{$\begin{array}{c}1 . \\
\text { year }\end{array}$} & $\mathrm{Sp}$ & 7.0 & 7.9 & 8.2 & 9.0 & 8.6 & 9.0 & 8.3 & 5.2 & 5.3 & 5.3 & 5.4 & 5.3 & 5.4 & 5.3 \\
\hline & $\mathrm{Su}$ & 6.9 & 8.2 & 8.0 & 8.9 & 8.2 & 8.9 & 8.2 & 5.0 & 5.0 & 5.0 & 5.1 & 5.2 & 5.1 & 5.1 \\
\hline & $\mathrm{Au}$ & 7.3 & 9.0 & 9.0 & 9.0 & 9.0 & 9.0 & 8.7 & 5.0 & 5.2 & 5.3 & 5.4 & 5.3 & 5.4 & 5.3 \\
\hline & $\mathrm{Wi}$ & 6.9 & 8.2 & 8.0 & 8.7 & 8.2 & 8.8 & 8.1 & 5.0 & 5.0 & 5.1 & 5.2 & 5.2 & 5.2 & 5.1 \\
\hline & Me. & 7.0 & 8.3 & 8.3 & 8.9 & 8.5 & 8.9 & 8.3 & 5.1 & 5.1 & 5.2 & 5.3 & 5.3 & 5.3 & 5.2 \\
\hline \multirow{5}{*}{$\begin{array}{c}2 . \\
\text { year }\end{array}$} & $\mathrm{Sp}$ & 7.9 & 9.0 & 9.0 & 9.0 & 9.0 & 9.0 & 8.8 & 5.3 & 5.4 & 5.3 & 5.4 & 5.4 & 5.3 & 5.4 \\
\hline & $\mathrm{Su}$ & 7.6 & 8.5 & 8.4 & 8.9 & 8.5 & 8.9 & 8.5 & 5.1 & 5.1 & 5.0 & 5.2 & 5.2 & 5.2 & 5.1 \\
\hline & $\mathrm{Au}$ & 7.9 & 9.0 & 9.0 & 9.0 & 9.0 & 9.0 & 8.8 & 5.2 & 5.2 & 5.2 & 5.5 & 5.4 & 5.4 & 5.3 \\
\hline & Wi & 7.4 & 8.4 & 8.2 & 8.9 & 8.5 & 8.8 & 8.4 & 5.1 & 5.0 & 5.1 & 5.2 & 5.1 & 5.1 & 5.1 \\
\hline & Me. & 7.7 & 8.7 & 8.7 & 9.0 & 8.8 & 8.9 & 8.6 & 5.2 & 5.2 & 5.2 & 5.3 & 5.3 & 5.3 & 5.3 \\
\hline \multirow{5}{*}{$\begin{array}{c}3 . \\
\text { year }\end{array}$} & $\mathrm{Sp}$ & 8.0 & 9.0 & 9.0 & 8.9 & 9.0 & 9.0 & 8.8 & 5.2 & 5.3 & 5.3 & 5.4 & 5.4 & 5.3 & 5.3 \\
\hline & Su & 7.8 & 8.6 & 8.5 & 9.0 & 8.6 & 8.9 & 8.5 & 5.1 & 5.1 & 5.1 & 5.2 & 5.1 & 5.2 & 5.1 \\
\hline & $\mathrm{Au}$ & 8.2 & 9.0 & 9.0 & 8.9 & 9.0 & 9.0 & 8.9 & 5.2 & 5.1 & 5.2 & 5.5 & 5.3 & 5.4 & 5.3 \\
\hline & Wi & 7.5 & 8.4 & 8.1 & 9.0 & 8.4 & 8.8 & 8.4 & 5.1 & 5.0 & 5.1 & 5.2 & 5.0 & 5.1 & 5.1 \\
\hline & Me. & 7.9 & 8.8 & 8.7 & 9.0 & 8.8 & 8.9 & 8.6 & 5.2 & 5.1 & 5.2 & 5.3 & 5.2 & 5.2 & 5.2 \\
\hline \multirow{5}{*}{ Mean } & $\mathrm{Sp}$ & 7.6 & 8.6 & 8.7 & 9.0 & 8.9 & 9.0 & 8.7 & 5.2 & 5.3 & 5.3 & 5.4 & 5.4 & 5.3 & 5.3 \\
\hline & $\mathrm{Su}$ & 7.4 & 8.4 & 8.3 & 8.9 & 8.4 & 8.9 & 8.4 & 5.1 & 5.1 & 5.0 & 5.2 & 5.2 & 5.2 & 5.1 \\
\hline & $\mathrm{Au}$ & 7.8 & 9.0 & 9.0 & 9.0 & 9.0 & 9.0 & 8.8 & 5.1 & 5.2 & 5.2 & 5.5 & 5.3 & 5.4 & 5.3 \\
\hline & Wi & 7.3 & 8.3 & 8.1 & 8.8 & 8.4 & 8.8 & 8.3 & 5.1 & 5.0 & 5.1 & 5.2 & 5.1 & 5.1 & 5.1 \\
\hline & Me. & 7.5 & 8.6 & 8.5 & 8.9 & 8.7 & 8.9 & 8.5 & 5.1 & 5.1 & 5.2 & 5.3 & 5.2 & 5.2 & 5.2 \\
\hline \multicolumn{2}{|c|}{${ }^{*} L S D 5 \%$} & $C: 0.03$ & & $S: 0.02$ & \multicolumn{2}{|c|}{$Y: 0.04$} & & \multicolumn{2}{|c|}{$C \times S: 0.03$} & $C \times Y$ : & 03 & \multicolumn{2}{|c|}{$S \times Y: 0.03$} & \multicolumn{2}{|c|}{$C \times S \times Y: 0.05$} \\
\hline \multicolumn{2}{|c|}{ * LSD 5\% } & $C: 0.02$ & & $S: 0.03$ & $Y: n$ & & & \multicolumn{2}{|c|}{$C \times S: 0.03$} & $C \times Y$ & 04 & \multicolumn{2}{|c|}{$S \times Y: 0.02$} & \multicolumn{2}{|c|}{$C \times S \times Y: 0.04$} \\
\hline
\end{tabular}

In terms of cultivars, results showed that the highest values were obtained from Merida and Turbo cultivars in all three years $(8.9,9.0,8.9)$ and in mean value $(8.9)$, whereas the lowest value for every year $(7.0,7.7,7.9)$ and in mean value (7.5) was seen in the Apache cultivar.

Results demonstrated that from highest to lowest seasons ranked as follows; autumn, spring, summer and winter. Data for the first year was poor because the newly established experiment had not yet exhibited its full performance. When cultivars used in the study are assessed with regard to years, the $2^{\text {nd }}$ and $3^{\text {rd }}$ years (8.6) performed better than the $1^{\text {st }}$ year $(8.3)$. The reason behind this was that plants could not exhibit their true performance in the establishment year, as mentioned when discussing seasonal performances. Different people could reach different results in the evaluation of turf color, as it is based on visual observation. According to the three years mean values, color values ranged between 7.5-8.9 and general average was 8.5 . The approximately one-point difference between the lowest mean (7.5) and the general average demonstrated that all the cultivars were acceptable in terms of color.
As for cultivar $\times$ season interactions, spring and autumn performances were higher than other seasons. Because the ecological conditions of Tokat occur close to perfect conditions for tall fescue, highly promising results were obtained from the cultivars. The Merida and Turbo cultivars, which reached a perfect score (9.0) in the spring of the first year, were accompanied by all the other varieties with a perfect score, except Apache, in spring and this was repeated in spring and autumn of the second and third years. The lowest values were seen in winter, which was followed by summer. Partial yellowing, due partly to the cold in winter and especially due to extreme heat on the tips of leaves after harvest in the summer, caused scores to relatively drop. Yellowing of the vegetation, caused by mowing wounds, was generally seen only on the leaf tips and not on the whole plant.

\subsection{Turf Texture}

Turf texture values $(\mathrm{mm})$ obtained in the study have been listed in Table 3. Evaluation of results in terms of cultivars revealed that the Merida, Turbo and SR8600 cultivars had widest turf texture in the first two years with $5.3 \mathrm{~mm}$, 
whereas for the third year and average value the Merida cultivar had widest turf texture with $5.3 \mathrm{~mm}$. The Apache and Eldorade cultivars had narrowest texture values in average with $5.1 \mathrm{~mm}$. All cultivars were under the "very coarse texture" category, as according to the classification by Acikgoz [1], Avcioglu [2] and Beard [3] they constituted textures wider than $4 \mathrm{~mm}$. When results were assessed in terms of seasons, the widest texture value was obtained in spring $(5.4 \mathrm{~mm})$ of the second year, while the lowest values were in summer and winter $(5.1 \mathrm{~mm})$ for all years. When data was assessed in terms of years, means were the same $(5.2 \mathrm{~mm})$ and statistically significant differences were not observed. Cultivar $\times$ season interactions showed that all cultivars formed wider leaf blades in spring and autumn than in summer and winter. This was because leaves develop better in cool periods and plants somewhat narrow their leaf blades in summer in order to reduce dehydration and in winter to protect from the cold $[1,2,3]$.

\subsection{Winter Endurance}

Winter endurance values were given in Table 4. The Merida and Turbo cultivars attained the highest winter endurance values with a score of 8.6 and the Apache cultivar had the lowest value with a score of 7.8. From study years, the third year surpassed the 8.0 score of the first year and the 8.3 score of the second year by obtaining a score of 8.5. Assessment of the data in terms of cultivar $\times$ year interactions revealed that the highest value was achieved in the third year by the Merida and Turbo cultivars with a score of 8.9 , while the lowest score was seen in the first year in the Apache cultivar with a score of 7.5 .

Collected data showed that the cultivars included in this experiment were not affected negatively by the winter conditions of the area.

Table 4. Winter Endurance and Turf Quality Scores by Seasons in Different Years (1-9 scale)

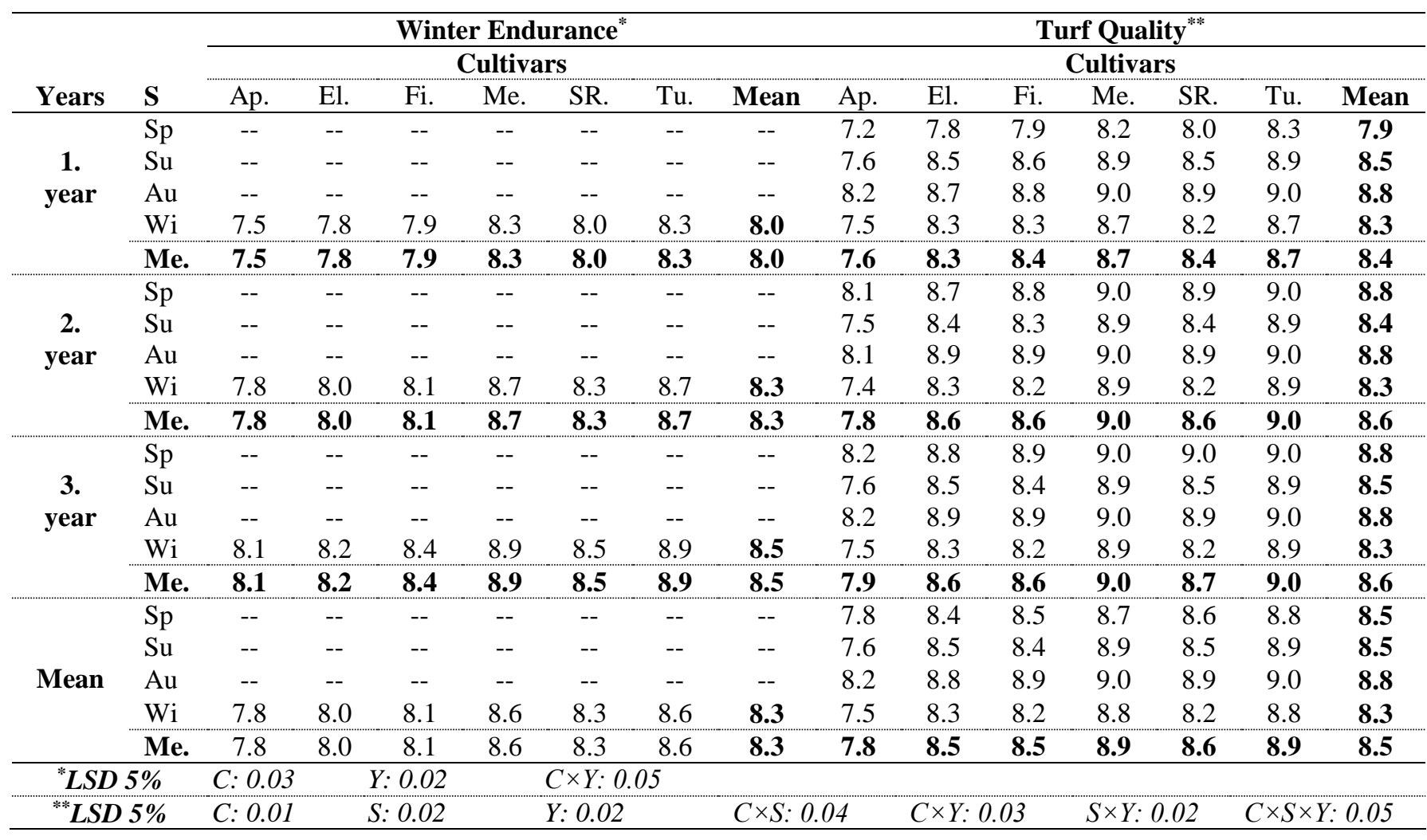

\subsection{Turf Quality}

Turf quality values for all three years of the study and the means values have been presented in Table 4 .

In terms of cultivars, the Merida and Turbo had the highest value with 8.7 the first, 9.0 the second and third years and a mean score of 8.9 , while the lowest value for all the years $(7.6,7.8,7.9)$ and mean value (7.8) was seen in the Apache cultivar.
In terms of seasons, autumn of the first year and spring and autumn of the second and third years displayed the same performance (8.8), spring of the first year ranked last with a score of 7.9, whereas in 2nd and 3rd years it was winter that ranked last with 8.3 . This was because spring of the first year was the season when the experiment was established and the green area had not yet been able to succeed in showing it performance. When results were assessed on the basis of cultivar $\times$ season, the Merida and Turbo cultivars showed highest value with 9.0 in autumn of the first year, and spring and autumn of the second and hird years, lowest 
values were seen in the Apache cultivar in spring of the first year (7.2), the year of establishment, and in winter of the second and third years $(7.4,7.5)$.

Assessment in terms of years indicated that the second and third years (8.6) exceeded the first year (8.4) and the general average was 8.5 .

\section{DISCUSSION}

When data obtained in the study is assessed as a whole; it is possible to say that the tall fescue plant adapted to the cool season ecological conditions of Tokat. This study supports the results of prior research $[12,13,16,25,26]$ carried out in Tokat. Furthermore, the results are in line with many studies [10,11,14,15,17,18,19] carried out in ecologies with similar cool climatic conditions as Tokat. However; the study results were higher and more favorable when compared to a study carried out in Izmir $[7,8,20,21,22,23,24]$ a city located in the Mediterranean climate zone with exceptionally hotter summers. This can be explained by cooler and rainier seasons in Tokat, with a more regular distribution of rainfall among seasons than Izmir.

Overall evaluation of the study results highlighted that the Merida and Turbo cultivars came to the forefront in all characteristics examined and although the Apache cultivar exhibited the lowest values, all cultivars possessed acceptable results.

According to the data obtained, all cultivars of tall fescue examined in the study can be considered as suitable cultivars for use in establisment of green areas in Tokat and similar ecological conditions.

\section{ACKNOWLEDGMENTS}

The author wish to thank Gokcehan Demir (Queens Public School 150, USA, and University of Bogazici, Faculty of Arts and Sciences, Department of Translation Science) for language editing.

\section{REFERENCES}

[1] E. Acikgoz, "Turfgrass Establishment and Maintenance Technique”, Cevre Ltd. Co. Press 4. 1, Ofset, January, OnMat Co., Bursa, pp: 203, (1994).

[2] R. Avcioglu, "Turf Technique (Turf Establishment \& Management)", Ege University Press, Izmir, Turkey, pp: 271, (1997).

[3] J.B. Beard, "Turf grass: Science and Culture", Prentice-Hall Inc., Englewood Cliffs, New Jersey, USA, (1973).

[4] G.E. Evans, "Tolerance of Selected Bluegrass and Fescue Tall to Simulated Human Traffic", Journal of Enviromental Horticulture, USA, 6: (1): 20, 10-14, (1988).

[5] J.B. Beard, "Turf grass water stress: drought resistance components, physiolagical mechanisms and species- genotypes diversity", Int. Turf. Soc. Res. J., 6: 23-28, (1989).

[6] M.A. Harivandi, “Tall Fescue Graining Popularity as a Turfgrass”, California Agriculture, 43, 121-125, (1987).

[7] A. Karakoc, "Investigations on the Suitability and Yield Characteristics of Some Turfgrass Green Areas in Aegean Coastline”, (Master Sci Thesis), Ege Univ., Institute of Science and Technology, Department of Field Crops, Izmir, $29 \mathrm{p},(1996)$.

[8] S. Canozer, "A Research on Growth Forms with Different Morphological Characters of Some Turfgrass that may be Suitable for Green Area in Aegean Coast Belt", (Master Sci Thesis), Ege Univ., Institute of Science and Tech., Dep., of Field Crops, Izmir, 31 p, (1997).

[9] N. Oral, "The Investigations on the Seed Mixtures, Seeding Rate, N-fertilization in the Turfs Established in Bursa Region", (Ph. D. Thesis), Uludag Univ., Ins. of Sci. and Technology, Department of Field Crops, Bursa, Turkey, 216 p, (1998).

[10] J.M. Van Huylenbroeck, P. Lootens and E. Van Bockstaele, "Photosynthetic characteristics of perennial ryegrass and red fescue turf-grass cultivars", Grass Forage Science, 54: 267-274, (1999).

[11] P. Annicchiarico, B. Lucaroni, E. Piano, L. Russi and F. Veronesi, "An Italian Network For The Evaluation of Turf Species and Varieties", Proceedings of the 22 nd Eucarpia Fodder Crops and Amenity Grasses Section Meeting, St Petersburg, Russia, pp: 78-80, (2000).

[12] M. Yilmaz, "Investigation on seed yield and turf properties of some grasses grown for turf grass and erosion control purposes in Tokat". (Ph. D Thesis), Ege Univ., Institute of Science and Technology, Department of Field Crops, Izmir, 220 p, (2000).

[13] M. Yilmaz, "Effects on performances of turfgrass of fertilizer application in different dozes in Tokat ecological conditions", Journal of the Agr. Fac. of Gaziosmanpasa Univ., 20: 117-122, (2003).

[14] Y. Jiang and B. Huang, "Effects of Calcium on Physiological Responses of Tall Fescue and Kentucky Bluegrass to Drought Stress", Int. Turfgrass Society Res. Journal, 9, 297-302, (2001).

[15] M. Volterrani, S. Miele, S. Magni, M. Gaetani and G. Pardini, "Bermuda-grass and seashore Paspalum winter overseeded with seven cool-season turf grasses”, Int. Turf. Soc. Res. J., 9: 957-961, (2001).

[16] M. Yilmaz and R. Avcioglu, "Investigations on The Turf Performances of Some Grasses Bare Sowing for Turfgrass and Erosion Control Purposes in Tokat-Kazova Conditions" Turkey VIII. Field Crops Congres, 19-22 October, Hatay, 604-608, (2009).

[17] L. Russi, P. Annicchiarico, P. Martiniello, C. Tomasoni, E. Piano and F. Veronesi, "Turf quality and reliability in varieties of four turf grass species in contrasting Italian environments", International Turfgrass Society Research J., 9: 917-921, (2004).

[18] P. Martiniello, "Variability of turf quality and phytocoenoses in areas of play in football grounds in Mediterranean environments", Agricultural Med. 135: 209220, (2005). 
[19] P. Martiniello and E. D’Andrea, “Cool-season turf grass species adaptability in Mediterranean environments and quality traits of varieties", Nec. Inf., 25: 234-242, (2005).

[20] G. Demiroglu, H. Geren, B. Kir and R. Avcioglu, "Performances of some cool season turf grass cultivars in mediterranean environment: II. Festuca arundinacea Scherb., Festuca ovina L., Festuca rubra spp. rubra L., Festuca rubra spp. trichophylla Gaud and Festuca rubra spp. commutata Gaud”, Turkish J. Field Crops, 15: 180187, (2010).

[21] G. Demiroglu, R. Avcioglu, B. Kir and A. Salman, "Investigations on texture weed invasion and density features of some cool season turf grass cultivars in Mediterranean environment”, Int. J. Agric. Biology, 13: 461-468, (2011).

[22] B. Kir, R. Avcioglu, G. Demiroglu and A. Simic, "Performances of Some Cool Season Turfgrass Species in Mediterranean Environment: I. Lolium perenne L., Festuca arundinacea Schreb., Poa pratensis L. and Agrostis tenuis Sibth”, Turkish Jou. of Field Crops, 15: 174-179, (2010).

[23] A. Salman and R. Avcioglu, "Performances of Some Cool Season Turf Grasses in Different Fertilizer Doses", Ege University, Journal of Faculty of Agriculture, 47: (3), 309-319, (2010).
[24] A. Salman, R. Avcioglu, M. Yilmaz, and G. Demiroglu, "Performances of Newly Introduced Festuca arundinacea Schreb. Cultivars Versus Lolium perenne L., in a Mediterranean Environment", Turkish Jurnal of Field Crops, 16(2); 215-219, 2011.

[25] M. Yilmaz, G. Demiroglu, A. Salman and R. Avcioglu, "Determination of some properties of different doses of fertilizers applied in a turfgrass", Turkey 9. Field Crops Congres, 12-15 September, Bursa, Turkey, 16961701, (2011).

[26] M. Yilmaz, A. Salman and R. Avcioglu, "Investigations on The Quantitative Properties of Some Tall Fescue (Festuca arundinacea Schreb.) Cultivars Under Tokat Ecological Conditions", Turkey 9. Field Crops Congres, 10-13 September, Konya, Turkey, 614-619, (2013).

[27] A.R. Brohi and A. Aydeniz, "Fertilizers and Fertilization”, Cumhuriyet Univ., Agr. Fac. Press: 10, Course Book: 3, Tokat, 880 p, (1991).

[28] K.N. Morris and R.C. Sherman, "The National Turfgrass Evaluation Program: Assessing New and Improved Varieties", Diversity, 16: 19-22, (2000).

[29] N. Acikgoz, E. Ilker and A. Gokcol, "Assessment of Biological Research on the Computer", Ege U., TOTEMSTAT, Izmir, (2004). 